\title{
Desempenho produtivo de matrizes de corte submetidas a dietas contendo aflatoxinas e glucomananos esterificados como adsorventes
}

\author{
Rodrigo Uttpatel ${ }^{1}$, Alexandre Pires Rosa ${ }^{2}$, Janio Morais Santurio ${ }^{3}$, Anelcir Scher ${ }^{1}$, Catarina \\ Stefanello ${ }^{4}$, Vinicius Duarte ${ }^{5}$ \\ 1 Programa de Pós-graduação em Zootecnia, UFSM, Santa Maria, RS, Brasil. \\ 2 Departamento de Zootecnia, Laboratório de Avicultura, UFSM, Santa Maria, RS, Brasil. \\ ${ }^{3}$ Departamento de Microbiologia, Laboratório de Pesquisas Micológicas, UFSM, Santa Maria, RS, Brasil. \\ ${ }^{4}$ Curso de Zootecnia, UFSM, Santa Maria, RS, Brasil. \\ ${ }^{5}$ Curso de Medicina Veterinária, UFSM, Santa Maria, RS, Brasil.
}

RESUMO - Este trabalho foi realizado com o objetivo de avaliar o desempenho produtivo de matrizes de corte submetidas a dietas contendo aflatoxinas e adsorvente à base de glucomananos esterificados. Foram utilizados 300 fêmeas e 40 machos da linhagem Ross 308 alojados em 20 boxes experimentais na fase de 61 a 72 semanas de idade. Da 61aa à 68aㅡ semana, as aves receberam dietas contendo três níveis de aflatoxina $(0 ; 0,500 ; 0,750 \mathrm{mg} / \mathrm{kg})$ em combinação ou não a adsorvente $(0,10 \%)$ e, nas quatro últimas semanas, receberam dietas isentas de aflatoxina e adsorvente. As aves foram distribuídas em delineamento inteiramente casualizado em esquema fatorial (níveis de aflatoxina vs níveis de adsorvente) com 4 repetições, cada uma de 15 fêmeas e 2 machos. A partir da 65aㅗ semana, as aves alimentadas com dietas contendo aflatoxina e adsorvente apresentaram menor taxa de postura em relação àquelas que receberam dietas comuns, sem esses aditivos. O peso corporal das matrizes, assim como o peso, o peso específico dos ovos, a eclodibilidade, e a qualidade dos pintos produzidos não são afetados pelos níveis de aflatoxinas e adsorvente presentes na dieta.

Palavras-chave: glucomananos esterificados, micotoxinas, produção de ovos

\section{Productive performance of broiler breeders fed diets containing aflatoxins and esterified glucomannan as adsorbents}

\begin{abstract}
The objective of this study was to evaluate the productive performance of broiler breeder hens fed diets containing aflatoxins and adsorbent on the basis of esterified glucomannan. It was used 300 Ross 308 females and 40 males broiler breeders, housed in 20 experimental pens in the 61-72 week of age phase. From the $61^{\text {st }}$ to the $68^{\text {th }}$ week, birds were fed diets containing three levels of aflatoxin $(0 ; 0.500 ; 0.750 \mathrm{mg} / \mathrm{kg})$ combined or not to adsorbent $(0.10 \%)$ and on the last four weeks they received diets without aflatoxin and adsorbent. The birds were distributed in a complete randomized design in a factorial scheme (levels of aflotoxin vs levels of adsorbents) with 4 replicates, each one with 15 females and 2 males. From the $65^{\text {th }}$ week, birds fed diets with aflotoxin and adsorbent showed lower laying rate compared to those fed regular diets, without those additives. Body weight of the breeders as well as egg weight, specific egg weight, hatchability and quality of chicks produced are not affected by the levels of aflatoxins and adsorbent present in the diet.
\end{abstract}

Key Words: egg production, esterified glucomannan, mycotoxins

\section{Introdução}

As aflatoxinas são produzidas pelos fungos Aspergillus flavus e A. parasiticus (Leeson et al., 1995), apresentam elevada toxicidade para várias espécies de animais domésticos, com efeitos tóxicos, mutagênicos e carcinogênicos, sobretudo no fígado (Osweiler, 1990). Essas toxinas podem causar inúmeros prejuízos no desempenho de matrizes de corte, tanto imediatos como tardios. A ingestão de aflatoxinas na ração é associada a perdas econômicas relacionadas a queda na taxa de postura (Hamilton \& Garlich, 1971), perda de peso, queda no consumo de alimento, baixa eclodibilidade (Trucksses et al., 1983), diminuição no peso dos ovos e do volume espermático (Lesson et al., 1995).

Os efeitos das aflatoxinas na produção de ovos não são imediatos; tornam-se perceptíveis somente após alguns dias ou semanas, em virtude da presença de folículos no trato reprodutivo das aves antes do consumo das micotoxinas (Vieira, 1995). Além disso, a queda na 
postura é precedida pela redução de proteínas e lipídeos nos níveis sanguíneos.

A forma mais usual de reduzir os efeitos negativos das aflatoxinas é a utilização de adsorventes minerais e biológicos na dieta (Pemberton \& Simpson, 1991). Entretanto, alguns adsorventes podem prejudicar a utilização de nutrientes e apresentam taxa de inclusão elevada nas dietas (Kubena et al., 1993; Parlat et al., 1999; Maiazzo et al., 2000; Rosa et al., 2001).

Estudos avaliando o uso de glucomananos esterificados (0,5 e 1,0 g/kg de ração) e aflatoxinas ( 0,05 até $5,0 \mathrm{mg} / \mathrm{kg}$ ) têm comprovado a capacidade de reverter total ou parcialmente os efeitos deletérios das aflatoxinas sobre o desempenho, os parâmetros hematológicos e a resposta imune em frangos de corte (Raju \& Devegowda, 2000; Aravind et al., 2003).

Este estudo foi realizado com os objetivos de identificar os problemas ocasionados pela presença de aflatoxinas nas dietas sobre o desempenho de matrizes de corte e investigar a possível ação dos glucomananos esterificados na adsorção de aflatoxinas.

\section{Material e Métodos}

O experimento foi conduzido no Laboratório de Avicultura (LAVIC) do Departamento de Zootecnia da Universidade Federal de Santa Maria (UFSM) utilizando-se 300 fêmeas e 40 machos de matrizes de corte da linhagem Ross 308 com 60 semanas de idade alojados em 20 boxes de $7 \mathrm{~m}^{2}$.

O experimento foi dividido em três períodos: a $60^{\mathrm{a}}$ semana de idade foi considerada fase pré-experimental, para adaptação das aves, com oferta de dieta padrão, isenta de aflatoxinas. Ao final dessa fase, as fêmeas apresentavam peso médio de $3,720 \mathrm{~kg}$ e taxa de postura de $63,23 \%$ e os machos, peso médio de 4,860 kg. Da 61a à 68aㅡ semana, as aves foram submetidas às dietas experimentais, contendo ou não aflatoxinas, e, da 69aa $72^{\underline{a}}$ semana, foram alimentadas com dietas isentas de aflatoxinas e adsorventes, com objetivo de verificar efeito residual.

As dietas experimentais foram formuladas com três níveis de aflatoxina (0; 0,500; e 0,750 mg/kg de ração) em combinação ou não a um adsorvente (glucomananos esterificado) no nível de $0,10 \%$. A água foi fornecida à vontade e a ração controlada conforme quantidade prevista no manual da linhagem para cada semana de produção. Os ovos eram coletados quatro vezes ao dia e submetidos à classificação, sendo selecionados para incubação somente os ovos limpos de ninho e sem deformações de casca. Depois de classificados, os ovos passaram por um processo de desinfecção gasosa, com a utilização de 7,0 g de permanganato de potássio e $14 \mathrm{~mL}$ de formol (37\%) para cada $\mathrm{m}^{3}$ de área. Após a desinfecção, foram armazenados em sala com temperatura entre 18 e $23^{\circ} \mathrm{C}$.

Para avaliar a eclodibilidade (eclosão dos ovos férteis), foram feitas duas incubações: a primeira, utilizando os ovos produzidos na $64^{\mathrm{a}}$ semana, e a segunda, os ovos produzidos na 68 ${ }^{\text {a }}$ semana de idade das matrizes. Em ambas as incubações, foram utilizados 50 ovos por repetição, com período médio de estoque de quatro dias, totalizando 200 ovos para cada dieta. O processo de incubação seguiu os padrões normais de incubação, de modo que no $18^{\underline{0}}$ dia todos os ovos foram transferidos para um nascedouro. No $21^{\text {o }}$ dia de incubação, no momento da retirada dos pintos do nascedouro, avaliou-se o número de ovos eclodidos e procedeu-se à avaliação fenotípica dos pintos, classificando-os em pintos de primeira (fenotipicamente perfeitos) e pintos de segunda qualidade (pintos com problemas locomotores, má cicatrização umbilical e excessivamente úmidos).

Uma vez por semana, 30 ovos provenientes das matrizes submetidas a cada dieta foram pesados e submetidos à verificação do peso específico em soluções salinas com densidades de 1,075, 1,080, 1,085, 1,090 e 1,095. Os ovos submetidos a esse procedimento não foram incubados.

A dieta basal foi formulada à base de milho e farelo de soja e as aflatoxinas adicionadas (AFB1: 86\%; AFB2: 8,5\%; AFG1: 3,8\% e AFG2: 1,7\%) foram produzidas pelo Laboratório de Pesquisas Micológicas (LAPEMI), segundo metodologia licenciada pelo Ministério da Agricultura, sob n ${ }^{\circ}$ 21042:002340/2003-18-RS.

Os parâmetros utilizados para avaliar os efeitos das aflatoxinas no desempenho produtivo de matrizes de corte foram: peso corporal das fêmeas, taxa de postura, massa de ovos, peso dos ovos, peso específico, eclodibilidade e qualidade dos pintos. Para determinar o peso médio das aves, semanalmente foram pesadas todas as aves de cada unidade experimental. A taxa de postura expressa a produção de ovos em relação ao número médio de aves na semana. A massa de ovos foi calculada pela seguinte fórmula: Massa de ovos $=$ (taxa de postura $\times$ peso médio dos ovos $) / 100$.

As aves foram distribuídas em delineamento inteiramente casualizado, em esquema fatorial incompleto (níveis de aflatoxinas vs níveis de adsorvente), totalizando 5 dietas, cada uma avaliada com quatro repetições de 15 fêmeas e 2 machos. Todas as variáveis avaliadas foram analisadas no mesmo delineamento. A análise estatística foi realizada pelo programa estatístico SAS (Statistical Analysis System, 2000) e os dados submetidos à análise de variância e ao teste Tukey a 5\% de significância. 


\section{Resultados e Discussão}

Em nenhuma das semanas do estudo, o peso corporal (Tabela 1) das matrizes foi afetado $(\mathrm{P}>0,05)$ pelo uso de aflatoxinas e adsorvente utilizados nas dietas. Ressalta-se que as aves receberam as mesmas quantidades de ração, pois estavam em programa de alimentação diário controlado. Esses resultados são semelhantes aos obtidos por Zaghini et al. (2005), que submeteram poedeiras ao consumo de rações contendo aflatoxina $(2,5 \mathrm{mg} / \mathrm{kg}$ de ração), com ou sem adição de mananoligossacarídeos, e não observaram diferença no peso corporal.
A produção de ovos (Tabela 2) da 61aa 64 a semana não foi afetada pelos níveis de aflatoxinas e adsovente utilizados nas dietas. A partir da 65ํㅗ semana, houve uma redução na taxa de postura nas aves que receberam as dietas com aflatoxinas (0,500 e $0,750 \mathrm{mg} / \mathrm{kg}$ ). A adição de adsorvente na dieta também provocou redução na taxa de postura e essa redução se manteve mesmo após a retirada dos aditivos, fato que diverge do observado por Zaghini et al. (2005) e Fernandes (2004), que avaliaram matrizes de corte alimentadas com dietas contendo aflatoxinas $(0,250 ; 0,500$ e $0,750 \mathrm{mg} / \mathrm{kg}$ de ração) da $49^{\underline{a}}$ à $53^{\underline{a}}$ semana de idade e não observaram efeitos negativos sobre a taxa de postura e o

Tabela 1 - Peso corporal de matrizes submetidas a dietas contendo aflatoxinas e adsorvente

\begin{tabular}{|c|c|c|c|}
\hline \multirow[t]{2}{*}{ Fator } & \multicolumn{3}{|c|}{ Fase (semanas) } \\
\hline & 61 a 64 & 65 a 68 & 69 a 72 \\
\hline \multicolumn{4}{|c|}{ Nível de aflatoxinas (mg/kg de ração) } \\
\hline $0 \mathrm{mg}$ & $3,88 \pm 0,05$ & $3,92 \pm 0,07$ & $4,01 \pm 0,07$ \\
\hline $0,500 \mathrm{mg}$ & $3,93 \pm 0,03$ & $4,04 \pm 0,04$ & $4,10 \pm 0,05$ \\
\hline $0,750 \mathrm{mg}$ & $3,89 \pm 0,02$ & $4,00 \pm 0,03$ & $4,03 \pm 0,03$ \\
\hline Valor de $\mathrm{P}$ & 0,6269 & 0,4380 & 0,4918 \\
\hline \multicolumn{4}{|l|}{ Nível de adsorvente } \\
\hline $0 \%$ & $3,89 \pm 0,02$ & $3,96 \pm 0,03$ & $4,02 \pm 0,03$ \\
\hline $0,10 \%$ & $3,92 \pm 0,02$ & $4,05 \pm 0,03$ & $4,10 \pm 0,04$ \\
\hline Valor de $\mathrm{P}$ & 0,4536 & 0,2127 & 0,1656 \\
\hline \multicolumn{4}{|c|}{ Combinação aflatoxinas + adsorvente } \\
\hline $0 \mathrm{mg}+0 \%$ & $3,88 \pm 0,05$ & $3,92 \pm 0,07$ & $4,01 \pm 0,07$ \\
\hline $0,500 \mathrm{mg}+0 \%$ & $3,90 \pm 0,05$ & $3,99 \pm 0,07$ & $4,03 \pm 0,07$ \\
\hline $0,500 \mathrm{mg}+0,10 \%$ & $3,95 \pm 0,02$ & $4,09 \pm 0,05$ & $4,16 \pm 0,05$ \\
\hline $0,750 \mathrm{mg}+0 \%$ & $3,89 \pm 0,04$ & $3,97 \pm 0,04$ & $4,01 \pm 0,04$ \\
\hline $0,750 \mathrm{mg}+0,10 \%$ & $3,90 \pm 0,02$ & $4,02 \pm 0,03$ & $4,05 \pm 0,04$ \\
\hline Valor de $\mathrm{P}$ & 0,6280 & 0,6061 & 0,4482 \\
\hline $\mathrm{CV} \%$ & 1,99 & 2,67 & 2,72 \\
\hline
\end{tabular}

Tabela 2 - Produção de ovos de matrizes submetidas a dietas contendo aflatoxinas e adsorvente

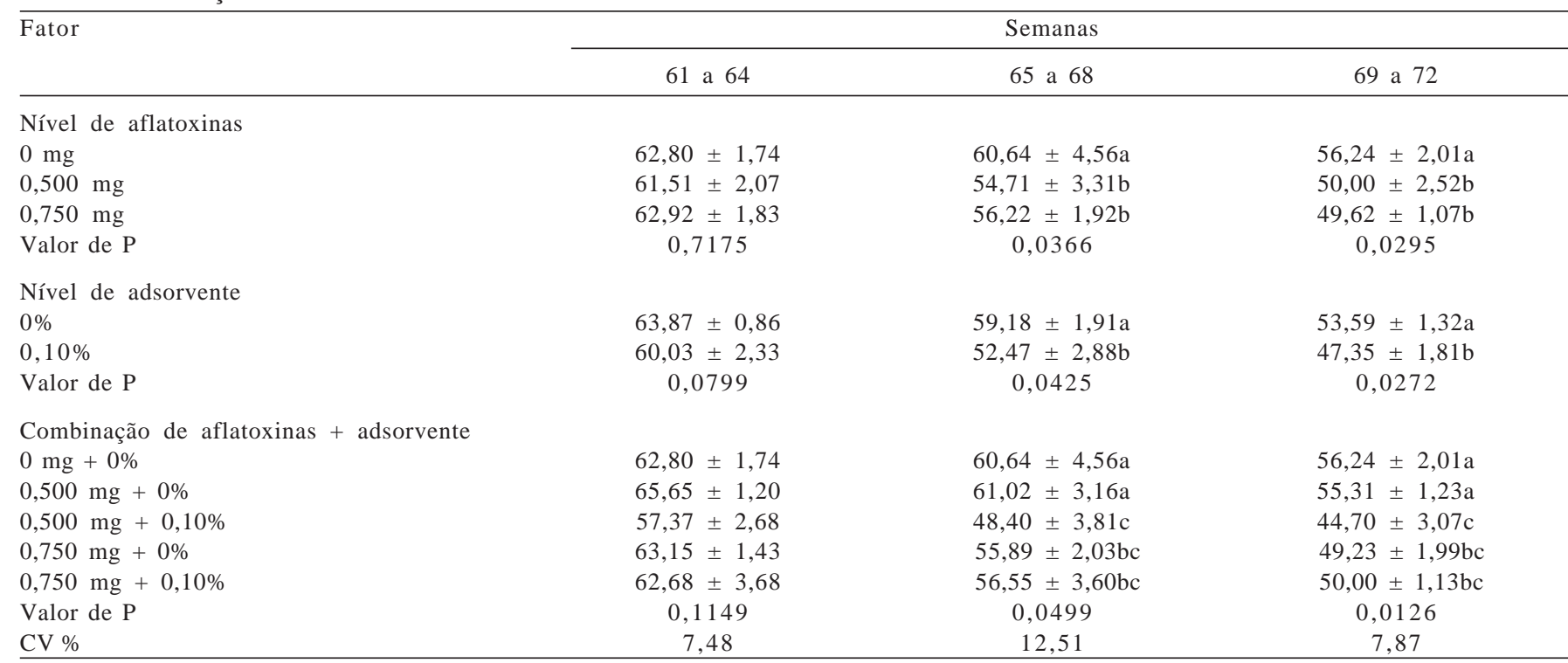


peso corporal das aves. Na fase da 65 à à $68^{\underline{a}}$ semana, as aves alimentadas com a dieta com a combinação de $0,500 \mathrm{mg}$ de aflatoxinas + adsorvente e com a dieta formulada com 0,750 mg de aflatoxina, com ou sem adsorvente, apresentaram menor produção de ovos em comparação às matrizes alimentadas com dietas contendo até $0,500 \mathrm{mg}$ de aflatoxinas/kg sem adsorvente. Esse efeito manteve-se durante o período subsequente, quando as matrizes receberam dietas isentas de aflatoxinas e adsorvente.

A massa de ovos (Tabela 3), uma derivação da taxa de postura, mostrou resposta similar à da produção de ovos, com valores mais baixos para as aves alimentadas com as dietas contendo aflatoxinas. O mesmo foi observado para as dietas contendo adsorvente. No entanto, esse perâmetro foi afetado apenas no último período de avaliação. O peso médio dos ovos (Tabela 4) não foi influenciado pelos aditivos, fato que está de acordo com relatos de Oliveira et al. (2001), que, em pesquisa com poedeiras, não observaram efeito da aflatoxina B1 sobre o peso de ovos. O peso específico dos ovos (Tabela 5) não apresentou qualquer diferença significativa, confirmando observações de Washburn et al. (1985) de que o fornecimento de aflatoxinas no nível de $5 \mathrm{mg} / \mathrm{kg}$ de ração não teve efeito sobre o peso específico dos ovos. De acordo com Vieira (1995), a aflatoxicose é responsável pela redução no tamanho dos ovos, que é acompanhada de redução proporcional da

Tabela 3 - Massa de ovos de matrizes submetidas a dietas contendo aflatoxinas e adsorvente

\begin{tabular}{|c|c|c|c|}
\hline Fator & \multicolumn{3}{|c|}{ Fase (semanas) } \\
\hline \multicolumn{4}{|l|}{ Nível de aflatoxinas } \\
\hline $0,500 \mathrm{mg}$ & $43,04 \pm 1,51$ & $38,43 \pm 2,27$ & $35,69 \pm 1,75 b$ \\
\hline $0,750 \mathrm{mg}$ & $43,80 \pm 1,34$ & $39,13 \pm 1,65$ & $35,45 \pm 0,79 b$ \\
\hline Valor de $\mathrm{P}$ & 0,6893 & 0,9466 & 0,0315 \\
\hline $0 \%$ & $44,80 \pm 0,59$ & $41,20 \pm 1,44$ & $38,25 \pm 0,84 a$ \\
\hline $0,10 \%$ & $41,58 \pm 1,62$ & $36,57 \pm 2,03$ & $33,86 \pm 1,41 b$ \\
\hline Valor de $\mathrm{P}$ & 0,3920 & 0,1263 & 0,0440 \\
\hline \multicolumn{4}{|c|}{ Combinação aflatoxinas + adsorvente } \\
\hline $0 \mathrm{mg}+0 \%$ & $43,81 \pm 1,02$ & $41,54 \pm 3,44$ & $40,19 \pm 1,31 a$ \\
\hline $0,500 \mathrm{mg}+0 \%$ & $46,15 \pm 0,75$ & $42,38 \pm 2,23$ & $39,02 \pm 0,35 a$ \\
\hline $\mathrm{CV} \%$ & 7,53 & 13,97 & 8,35 \\
\hline
\end{tabular}

Tabela 4 - Peso médio dos ovosdas aves submetidas à dietas contendo aflatoxinas e adsorvente

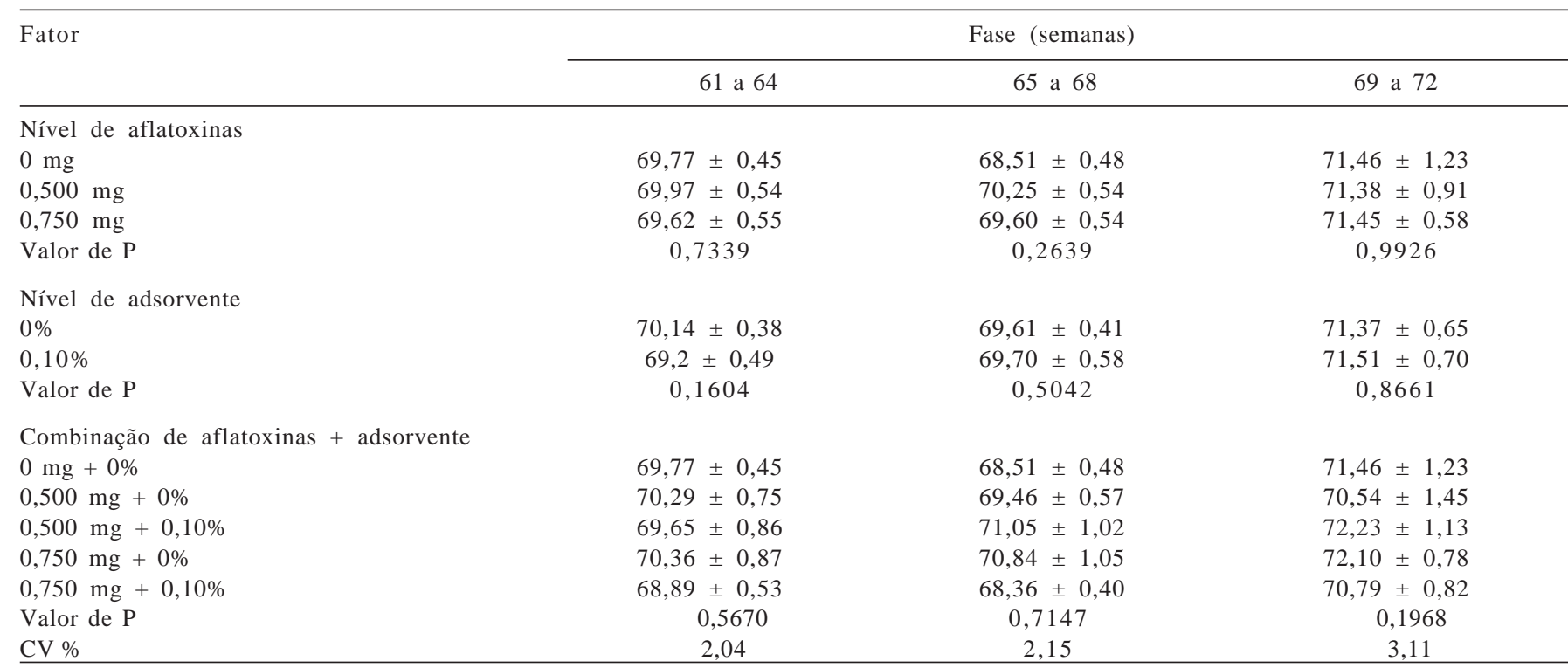


gema. Todavia, esse comportamento não é observado para a deposição de cálcio na casca do ovo.

A eclodibilidade (Tabela 6), assim como a qualidade dos pintos (Tabela 6), não foi influenciada pelas dietas, fato que diverge das afirmações de Qureshi et al. (1998) de que há transferência da aflatoxina da matriz para a progênie via ovo, resultando em mortalidade não explicada em frangos de corte e que a presença de aflatoxinas e seus metabólitos em ovos incubáveis pode resultar em progênie de má qualidade. Contudo, em seus estudos, esses autores encontraram efeito da aflatoxina sobre a eclodibilidade quando submeteram matrizes ao consumo de aflatoxinas no nível de $5 \mathrm{mg} / \mathrm{kg}$ de ração, nível significativamente superior ao utilizado neste estudo. Os dados obtidos na avaliação de parâmetros de incubação condizem parcialmente com os relatados por Fernandes (2004), que, avaliando baixos níveis de aflatoxinas na dieta de matrizes de corte por cinco semanas, não observou redução na eclodibilidade, no entanto, esse autor observou aumento no percentual de pintos de segunda e refugos em matrizes alimentadas com dietas contendo aflatoxinas $(0,250 \mathrm{e}$ $0,500 \mathrm{mg} / \mathrm{kg}$ de ração).

Tabela 5 - Peso específico dos ovos das matrizes submetidas à dietas contendo aflatoxinas e adsorvente

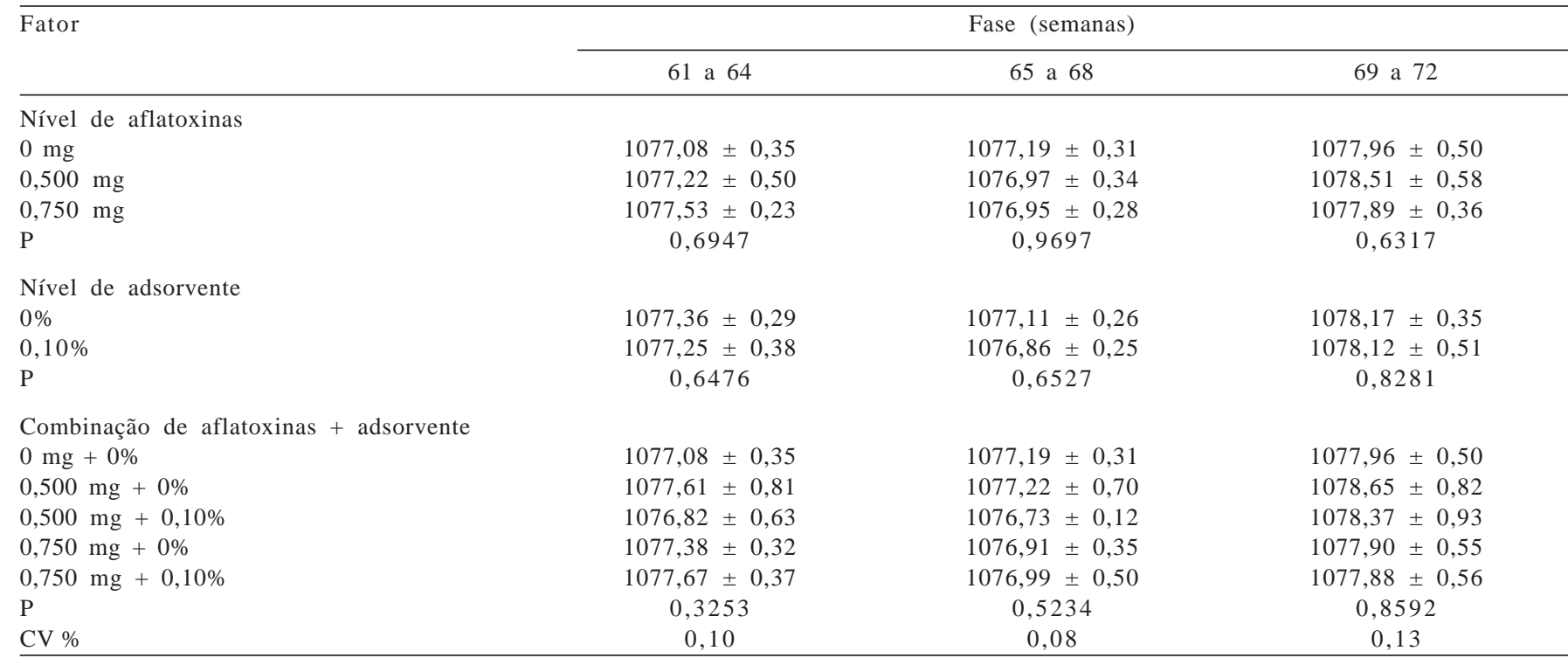

Tabela 6 - Eclodibilidade e qualidade de pintos de corte oriundos de matrizes alimentadas com níveis de aflatoxinas e adsorvente

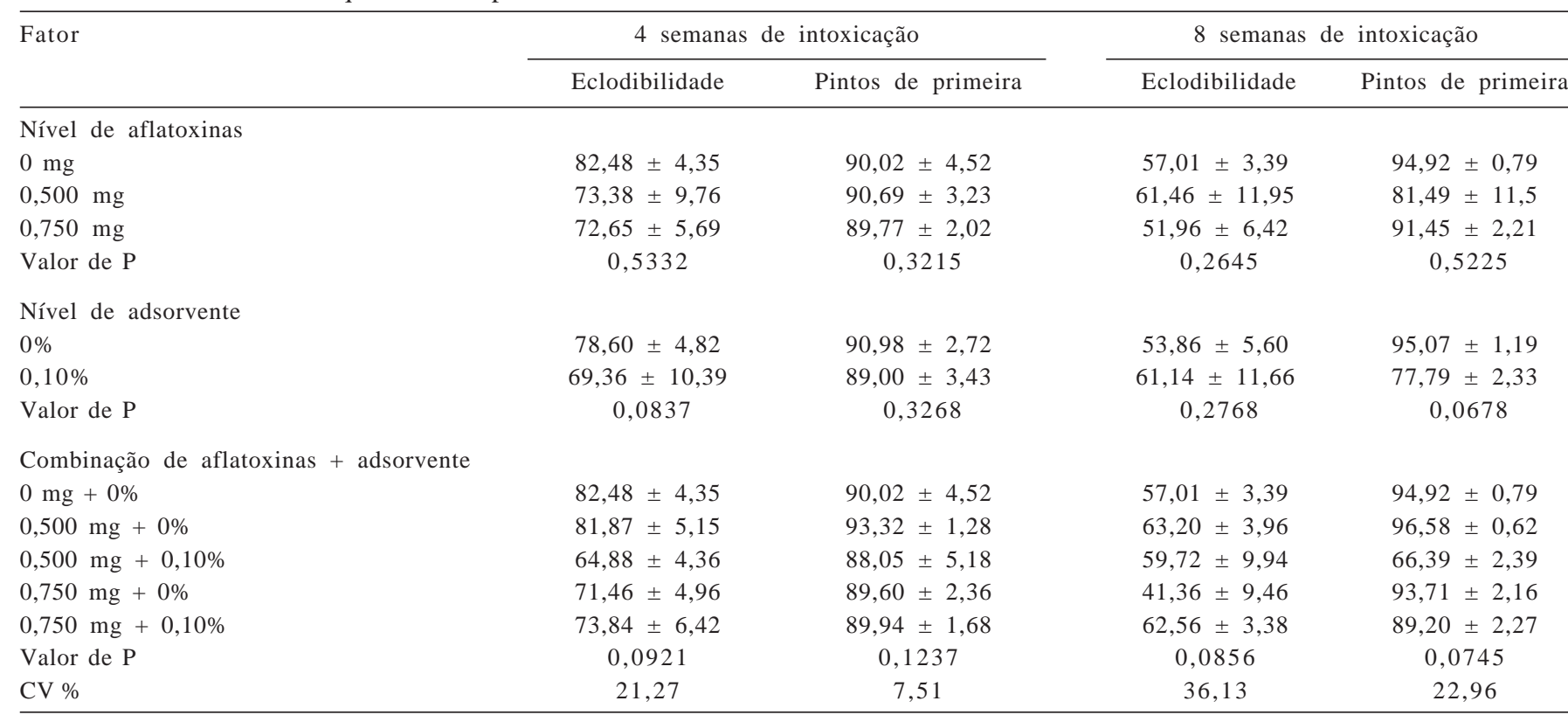




\section{Conclusões}

Os níveis de aflatoxinas e glucomananos esterificados avaliados neste estudo comprometem o desempenho produtivo de matrizes de corte, mas não prejudicam a eclodibilidade e a qualidade dos pintos produzidos.

\section{Agradecimentos}

Ao Conselho Nacional de Desenvolvimento Científico e Tecnológico (CNPq), pela concessão de bolsa ao segundo, quarto e sexto autores. Ao Laboratório de Avicultura (LAVIC) da Universidade Federal de Santa Maria (UFSM), pela infraestrutura para a realização do trabalho.

\section{Referências}

ARAVIND, K.L.; PATIL, V.S.; DEVEGOWDA, G. et al. Efficacy of esterified glucomannan to counteract mycotoxicosis in naturally contaminated feed on performance and serum biochemical, haematological parameters in broilers. Poultry Science, v.82, p.571-576, 2003.

DIAZ, D.E.; HAGLER JUNIOR, W.M.; HOPKINS, B.A. et al. Aflatoxin binders $\mathrm{I}$ : in vitro binding assay for aflatoxin $\mathrm{B}_{1}$ by several potential sequestering agents. Mycopathologia, v.156, p.223-226, 2002.

FERNANDES, A.J. Desempenho produtivo e reprodutivo de matrizes de corte alimentadas com dietas contendo doses crescentes de aflatoxinas. 2004. 65f. Dissertação (Mestrado em Zootecnia) - Programa de Pós-graduação em Zootecnia, Universidade Federal de Santa Maria, Santa Maria.

HAMILTON, P.B.; GARLICH, J.D. Aflatoxin as a possible cause of fatty liver syndrome in laying hens. Poultry Science, v.50, p.800-804, 1971.

KUBENA, L.F.; HARVEY, R.B.; HUFF, W.E. et al. Efficacy of a hydrated sodium calcium aluminosilicate to reduce the toxicity of aflatoxin and diacetoxyscirpenol. Poultry Science, v.72, p.91-59, 1993.

LEESON, S.; DIAZ, G.J.; SUMMERS, J.D. Poultry metabolic disorders and mytoxins. Guelph: University Books, 1995. p.249-280.

MAHESH, B.K.; DEVEGOWDA, G. Ability of aflatoxin binders to bind aflatoxin in contaminated poultry feed an in vitro study. In: WORLD'S POULTRY CONGRESS, 20., 1996, New Delhi. Proceedings... New Delhi, 1996. p.296.

MAIAZZO, R.; ROSA, C.A.; MAGNOLI, C. et al. Efficacy of synthetic zeolite to reduced the toxicity of aflatoxin in broiler chicks. Poultry Science, v.79, p.1-6, 2000.

OLIVEIRA, C.A.F.; ALBUQUERQUE, R.; CORREA, B. et al. Produção e qualidade dos ovos de poedeiras submetidas à intoxicação prolongada com aflatoxina B1. Arquivos do Instituto Biológico de São Paulo, v.68, n.2, p.1-4, 2001.

OSWEILER, G.D. Mycotoxins and livestock: what role do fungal toxins play in illness and production losses? Veterinary Medicine, v.85, p.89-94, 1990.

PARLAT, S.S.; YILDIZ, A.O.; OGUZ, H. Effect of clinoptilolite on fattening performance of Japanese quail (Coturnix coturnix japonica) during experimental aflatoxicosis. British Poultry Science, v.40, p.495-500, 1999.

PEMBERTON, A.D.; SIMPSON, J.J. The chemical degradation of mycotoxins. In: SMITH, J.E.; HENDERSON, R.S. (Eds.) Mycotoxins in animal foods. Boca Raton: CRC Press, 1991. p.797-813.

QURESHI, M.A.; BRAKE, J.; HAMILTON, P.B. et al. Dietary exposure of broiler breeders to aflatoxin results in immune dysfunction in progeny chicks. Poultry Science, v.77, p.812-819, 1998.

RAJU, M.V.L.N.; DEVEGOWDA, G. Influence of esterifiedglucomannan on performance and organ morphology, serum biochemistry and hematology in broilers exposed to individual and combined mycotoxicosis (aflatoxin, ochratoxin and T-2 toxin). British Poultry Science, v.41, p.640-650, 2000.

ROSA, A.P.; MALLMANN, C.A.; JASKULSKI, R.W. et al, Desempenho produtivo de matrizes de corte submetidas à intoxicação por aflatoxina e deoxynivalenol. In: CONFERÊNCIA APINCO DE CIÊNCIA E TECNOLOGIA AVÍCOLA, 2001, Campinas. Anais... Campinas: Fundação Apinco de Ciências e Tecnologia Avícolas, 2001. v.1, p.73.

STATISTICAL ANALYSES SYSTEM - SAS. SAS User's guide: statistics. Cary: SAS Institute, 2000. (CD-ROM).

TRUCKSSES, M.W.; STOLOFF, L.; YOUNG, K. et al. Aflatoxicol and aflatoxins B1 and M1 in eggs and tissues of laying hens consuming aflatoxin-contaminate feed. Poultry Science, v.62, p.2176-2182, 1983.

VIEIRA S.L. Micotoxinas e produção de ovos. In: SIMPÓSIO INTERNACIONAL SOBRE MICOTOXINAS E MICOTOXICOSES EM AVES, 1., 1995, Curitiba. Anais... Curitiba: Apinco, 1995. p.65-80.

WASHBURN, K.W.; WYATT, R.D.; POTTS, P.L. et al. Effects and mechanism of aflatoxin variation in shell strength. Poultry Science, v.64, p.1302-1305, 1985.

ZAGHINI, A.; MARTELli, G.; RONCADA, P. et al. Mannanoligosaccharides and aflatoxin B1 in feed for laying hens: effects on egg quality, aflatoxins B1 and M1 residues in eggs, and aflatoxin B1 levels in liver. Poultry Science, v.84, p.825-832, 2005. 